\title{
USING THE CASE RESEARCH APPROACH IN UNDERSTANDING THE EFFECT OF MANAGING CHANGE THROUGH TECHNOLOGY TO ACHIEVING STRATEGIC COMPETITIVENESS IN PRIVATE BANKS: GAINS AND PERILS
}

\author{
Dr. Elham Metwally, The American University in Cairo
}

dx.doi.org/10.18374/JIFE-13-2.1

\begin{abstract}
Issues pertaining to enhancing banks' competitiveness have been the foci of top executives worldwide. Of these issues are technology innovations which have affected the way most banks operate, deliver services, and compete. This paper examines the adoption of a cross-sectional exploratory and descriptive multiple-case study approach to explore, describe, and explain the effect of managing change through technology to achieving strategic competitiveness in the banking sector. The study, covering fifteen years (1990-2005), used such well suited qualitative research strategy in connection with theory to gain full understanding of a natural setting, and as a comprehensive method of substantiating or un-substantiating the research's topics of interest. In-depth semi-structured interviews were used as primary data collection techniques to obtain information from both industry authorities and top-level management in four banks; whereas, documentation and archival records were used as secondary sources with the purpose of enhancing an understanding of the background of the cases studied. The "Replication Logic" was followed, rather than the "Sampling Logic," in the selection of the four cases. The researcher followed the theoretical propositions, which induced the case studies, in analysing the data; and, the four banks were examined in depth to confirm or disconfirm the propositions derived from the literature review. The researcher used the pattern-matching mode of analysis to analyse multiple-case study design evidence. Further, the paper discusses the gains and perils of choosing the case study methodology in studying the research topic, and evaluates the study design according to two main criteria for judging measurement tools; these are validity and reliability.
\end{abstract}

Keywords: Case study research, qualitative research, methodological rigor, application of case research in the banking sector 